\title{
Luminescence and Structure of ZnO Grown by Physical Vapor Deposition
}

\author{
R. García-Gutiérrez, ${ }^{1}$ M. Barboza-Flores, ${ }^{1}$ D. Berman-Mendoza, ${ }^{1}$ \\ R. Rangel-Segura, ${ }^{2}$ and O. E. Contreras-López ${ }^{3}$ \\ ${ }^{1}$ Departamento de Investigación en Física, Universidad de Sonora, 83000 Hermosillo, SON, Mexico \\ ${ }^{2}$ División de Estudios de Posgrado, Facultad de Ingeniería Química (UMSNH), Ciudad Universitaria, Edificio V-1, \\ Morelia, MICH, Mexico \\ ${ }^{3}$ Centro de Nanociencias y Nanotecnología, Universidad Nacional Autónoma de México, Apdo. Postal 2681, \\ 22800 Ensenada, BC, Mexico
}

Correspondence should be addressed to D. Berman-Mendoza, daiber@cajeme.cifus.uson.mx

Received 15 August 2012; Revised 18 November 2012; Accepted 7 December 2012

Academic Editor: Markku Leskela

Copyright () 2012 R. García-Gutiérrez et al. This is an open access article distributed under the Creative Commons Attribution License, which permits unrestricted use, distribution, and reproduction in any medium, provided the original work is properly cited.

\begin{abstract}
Nanostructured $\mathrm{ZnO}$ was deposited on different substrates $\left(\mathrm{Si}, \mathrm{SiO}_{2}\right.$, and $\left.\mathrm{Au} / \mathrm{SiO}_{2}\right)$ by an enhanced physical vapor deposition technique that presents excellent luminescent properties. This technique consists in a horizontal quartz tube reactor that uses ultra-high purity $\mathrm{Zn}$ and UHP oxygen as precursors. The morphology and structure of $\mathrm{ZnO}$ grown in this work were studied by electron microscopy and X-ray diffraction. The XRD patterns revealed the highly crystalline phase of wurtzite polycrystalline structure, with a preferred (1011) growth direction. Room temperature cathodoluminescence studies revealed two features in the luminescence properties of the $\mathrm{ZnO}$ obtained by this technique, first a high-intensity narrow peak centered at $390 \mathrm{~nm}(\sim 3.2 \mathrm{eV})$ corresponding to a near band-to-band emission, and secondly, a broad peak centered around $517 \mathrm{~nm}(2.4 \mathrm{eV})$, the typical greenyellow luminescence, related to an unintentionally doped $\mathrm{ZnO}$.
\end{abstract}

\section{Introduction}

Zinc oxide $(\mathrm{ZnO})$ has been an object of growing attention in the last decade due to its potential applications in electronics and optoelectronics. $\mathrm{ZnO}$ is a wideband gap semiconductor with a hexagonal crystalline structure (wurtzite type) showing a direct band gap of $\sim 3.3 \mathrm{eV}$. As a direct wide band gap semiconductor material, $\mathrm{ZnO}$ has attracted much attention towards applications, such as UV photodetectors, solar cells, light emitting diodes and laser diodes $[1,2]$. Several techniques have been adopted to synthesize $\mathrm{ZnO}$ nanostructures such as metalorganic chemical vapor deposition (MOCVD) [3], microwave plasma deposition [4], hydrothermal synthesis [5-7], electrochemical deposition [8-11], and ultrasonic spray pyrolysis [12]. Nevertheless, physical vapor deposition (PVD) technique is an easy, reproducible, low-cost method that can be scaled up and used for the production of wide range of nanostructures such as nanowires, nanobelts, nanohelixes, nanorings, and nanoneedles [13-16].

In this work, nanostructured $\mathrm{ZnO}$ has been grown on different substrates $\left(\mathrm{Si}, \mathrm{SiO}_{2}\right.$, and $\left.\mathrm{Au} / \mathrm{SiO}_{2}\right)$ by physical vapor deposition technique; the nanostructures obtained were sheets and plaques.

\section{Experimental Procedure}

The schematic setup for the physical vapor deposition of $\mathrm{ZnO}$ is shown in Figure 1. The reactor consists of a quartz tube heated in a three-zone horizontal furnace. A boat with UHP $\mathrm{Zn}$ is placed at the first zone of the quart tube, and a boat that holds the substrates (silicon wafer, fused silica disk and a gold-covered fused silica disk) is placed in zone 2 .

The quartz tube used in this work was a $2.5^{\prime \prime}$ tube, but this system allows to change the size of the tube thus being able to scale up the deposits. This PVD method instead of 


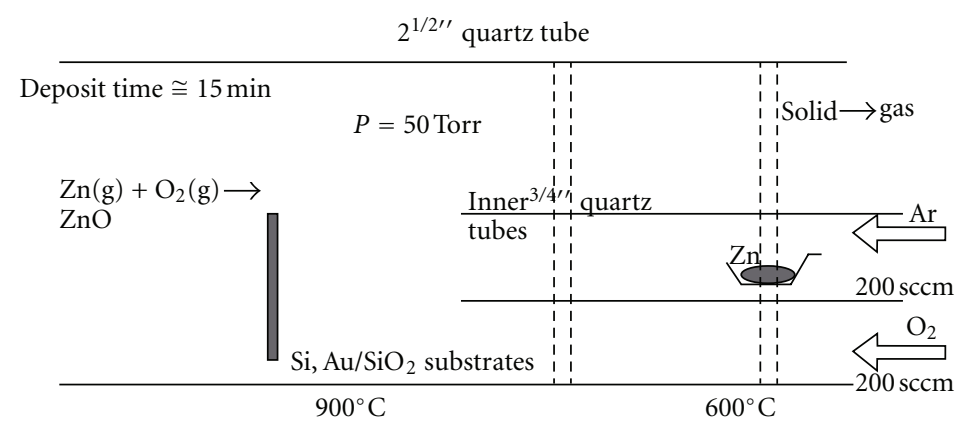

FIgURE 1: Experimental setup to grow ZnO by physical vapor deposition in a horizontal quartz tube reactor.

needing low pressure settings to work, it can deposit the required samples at atmospheric pressure. The normal PVD method uses a $\mathrm{ZnO}$ target where this improved PVD method uses a $\mathrm{Zn}$ target and UHP oxygen as reactant gas. This system allows doping the samples with different materials (such as $\mathrm{Al}, \mathrm{Ag}$, and In).

The following reactions take place in the quartz tube:

$$
\begin{aligned}
& \text { Zone } 1 \text { at } 600^{\circ} \mathrm{CZn}_{(\mathrm{l})} \longrightarrow \mathrm{Zn}_{(\mathrm{g})} \\
& \text { Zone } 2 \text { at } 900^{\circ} \mathrm{CZn}_{(\mathrm{g})}+\longrightarrow \mathrm{ZnO}_{(\mathrm{s})}+\frac{1}{2} \mathrm{O}_{2(\mathrm{~g})}
\end{aligned}
$$

A gold layer $(\sim 50 \mathrm{~nm})$ was deposited on a $1^{\prime \prime}$-diameter fused silica substrate by sputtering, with a following thermal treatment at $900^{\circ} \mathrm{C}$. This process made the gold film form disperse $\sim 100 \mathrm{~nm}$ size islands that act as catalysts and nucleation sites for $\mathrm{ZnO}$ nanorods.

Once the boats containing the substrates $\left(\mathrm{Si}, \mathrm{SiO}_{2}\right.$, and $\left.\mathrm{Au} / \mathrm{SiO}_{2}\right)$ and the $\mathrm{Zn}(\sim 1.5 \mathrm{~g})$ are placed inside the quartz tube, the tube is flushed with argon while being evacuated with a mechanical pump down to $1 \mathrm{~Pa}$. The temperature is increased, and when the central zone of the tube reaches $900^{\circ} \mathrm{C}$, the argon flushing and evacuation are stopped, and a flow of UHP oxygen is started through the $2.5^{\prime \prime}$ diameter tube $(200 \mathrm{sccm}, \sim 7000 \mathrm{~Pa})$. At that point the temperature at the entrance of the reactor is $600^{\circ} \mathrm{C}$, and the $\mathrm{Zn}$ starts to evaporate. The vapor is carried through an inner $3 / 4^{\prime \prime}$ diameter quartz tube by argon $(\sim 200 \mathrm{sccm})$. When the $\mathrm{Zn}$ vapor reaches zone 2 , at $900^{\circ} \mathrm{C}$, it is ready to react with the oxygen that is flowing by annular space. The $\mathrm{Zn}$ and the oxygen react on the surface of the substrate yielding $\mathrm{ZnO}$. The growth is maintained for around $15 \mathrm{~min}$. The boat with the substrate and the deposit $(\mathrm{ZnO})$ is moved rapidly to the coldest part of the reactor using a magnetic manipulator. After the system is cooled down to room temperature, the boat is taken out of the reactor. Then, $\mathrm{ZnO}$ samples are stored for later analysis.

The cathodoluminescence (CL) measurements were taken in a JEOL JSM 6300 scanning electron microscope equipped with a CL system. The following conditions were used: acceleration voltage $5 \mathrm{kV}$, beam current $300 \mathrm{pA}$, slit width $0.12 \mathrm{~mm}$, and spot size $2 \times 1.5 \mu \mathrm{m}$. The XRD measurements were done using the D500 SIEMENS diffractometer in a range of 10 to 70 degrees in position $2 \theta$ at room temperature. The following conditions were used: acceleration

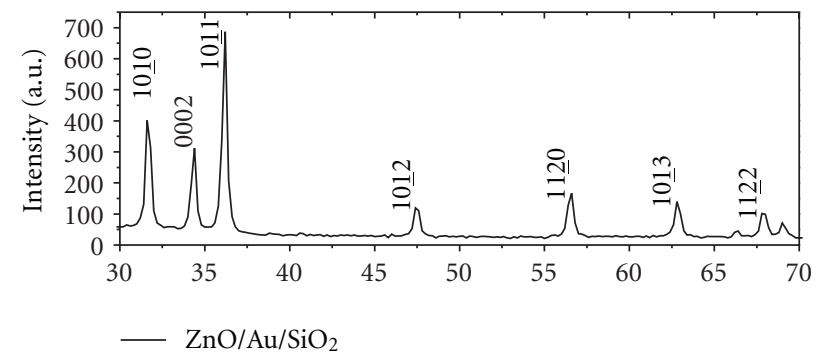

FIgURE 2: XRD diffraction pattern of $\mathrm{ZnO}$ grown by PVD.

voltage $5 \mathrm{Kv}$, beam current $300 \mathrm{pA}$, slit with $0.12 \mathrm{~mm}$, and spot size $2 \times 1.5 \mu \mathrm{m}$.

\section{Results and Discussion}

The crystalline structure of $\mathrm{ZnO} / \mathrm{Au} / \mathrm{SiO}_{2}$ was characterized using XRD as shown in Figure 2. The sharp diffraction pattern indicates that the sample exhibits hexagonal $\mathrm{ZnO}$ polycrystalline structure with a preferred growth direction (1011), with lattice constant of $a=3.248 \AA$ and $c=5.199 \AA$, which is reported in JCPDS (36-1451). The Scherrer formula was used for the calculation of the crystallite sizes, which is given by the following formula:

$$
D_{h k l}=\frac{K \lambda}{\beta \cos \theta},
$$

where $K$ is constant, $\beta$ is FWHM in radians, $\lambda$ is the wavelength of X-ray used, which was $1.5406 \AA$, and $\theta$ is the bragg angle, which was $18.1^{\circ}$. $K$ value is taken as 0.9 for the calculations. The crystallite size (D) calculated for $\mathrm{ZnO}$ nanostructures was approximately $50 \mathrm{~nm}$. Secondary electron images of $\mathrm{ZnO}$ grown in this work are shown in Figure 3. The morphology of the $\mathrm{ZnO}$ grown on (a) Si (100) and (b) $\mathrm{SiO}_{2}$ is very similar, mostly rectangular plaques (flat surfaces with average dimensions of $40 \mu \mathrm{m}$ length $\times 10 \mu \mathrm{m}$ width $\times 1 \mu \mathrm{m}$ thick) and nanowires, around $100 \mathrm{~nm}$ diameter and more than $100 \mu \mathrm{m}$ long. In contrast, the $\mathrm{ZnO}$ grown on Au nanoislands shows mainly rods and columns, with dimensions between 100 and $200 \mathrm{~nm}$ diameter and length between 1 and $4 \mu \mathrm{m}$. Figure 4 shows gold droplets formation after annealing of a $10 \mathrm{~nm}$ Au layer with narrow size particles 


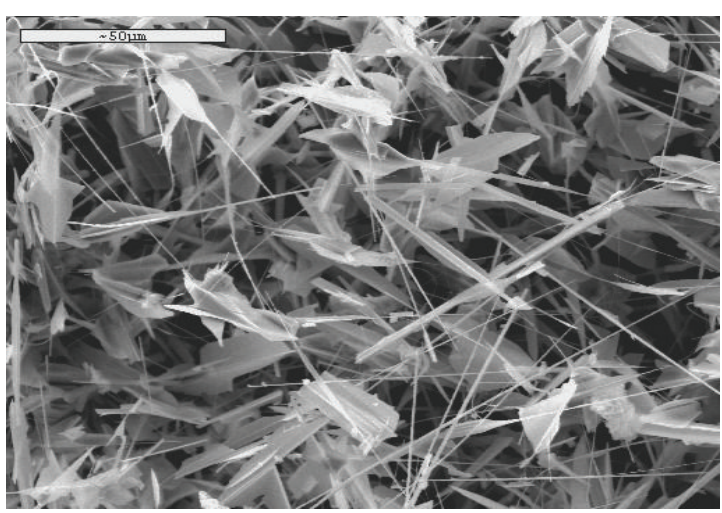

(a)

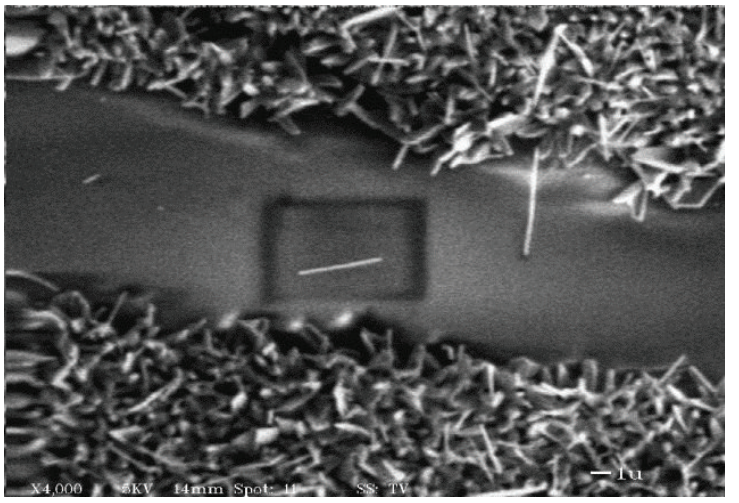

(c)

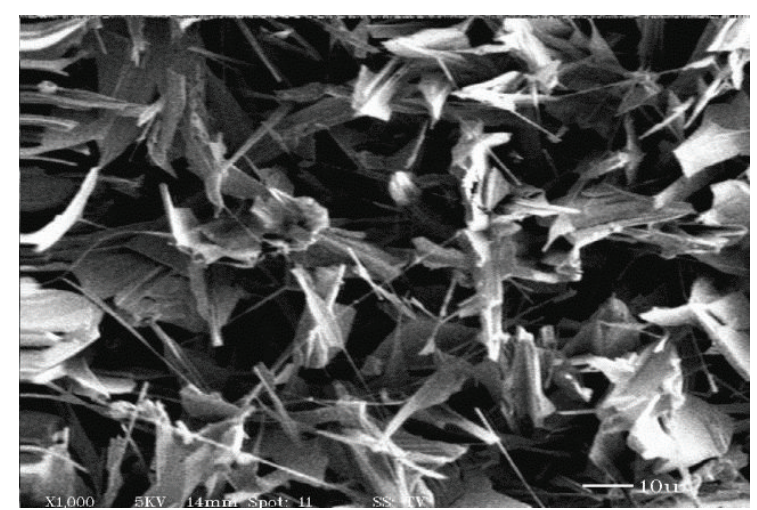

(b)

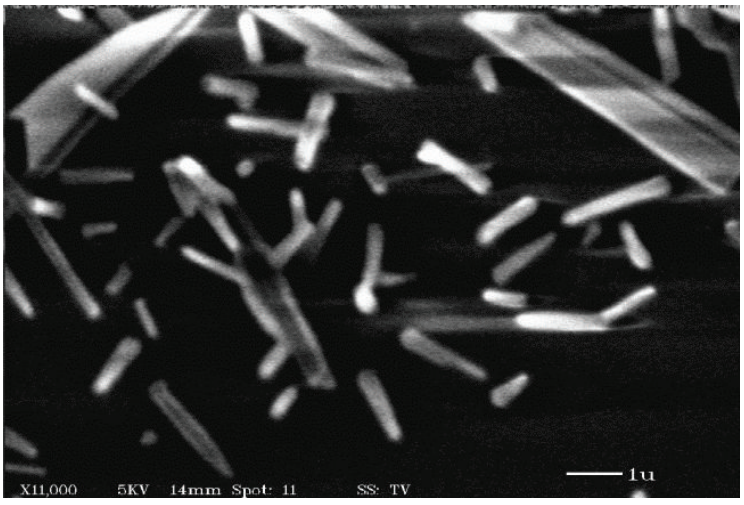

(d)

Figure 3: Secondary electron images of as-grown $\mathrm{ZnO}$. (a) on silicon (100), (b) on fused silica $\left(\mathrm{SiO}_{2}\right)$, and (c) and (d) on gold-covered fused silica $\left(\mathrm{Au} / \mathrm{SiO}_{2}\right)$.

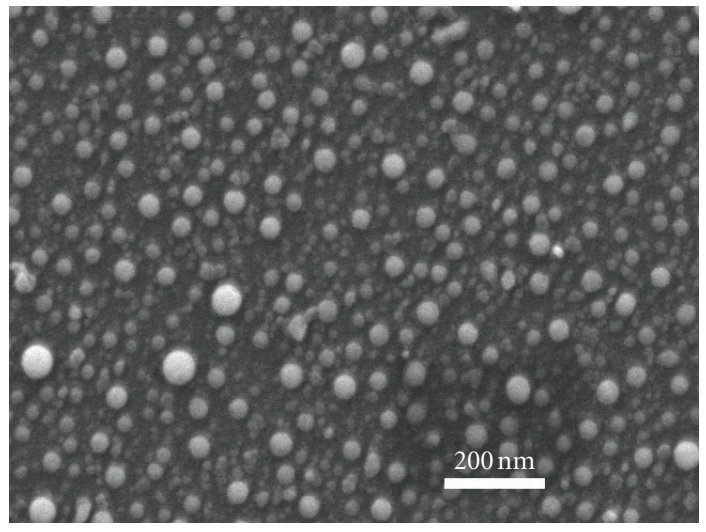

Figure 4: Gold islands after annealing of $10 \mathrm{~nm}$ Au layer over fused silica.

distributed between 50 and $100 \mathrm{~nm}$. It was found that the $\mathrm{Au}$ droplets promote the crystal growth and nucleation of $\mathrm{ZnO}$ over them. This means that the typical crystalline structure of $\mathrm{ZnO}$ is presented when deposited in $\mathrm{SiO}_{2}$, but when in presence of Au droplets, it functions as nucleation center and catalyst, improving the column growth of $\mathrm{ZnO}$.

In addition, XRD spectra confirmed that the $\mathrm{ZnO}$ grown by this PVD technique shows a hexagonal wurtzite structure. Cathodoluminescence has been used to further

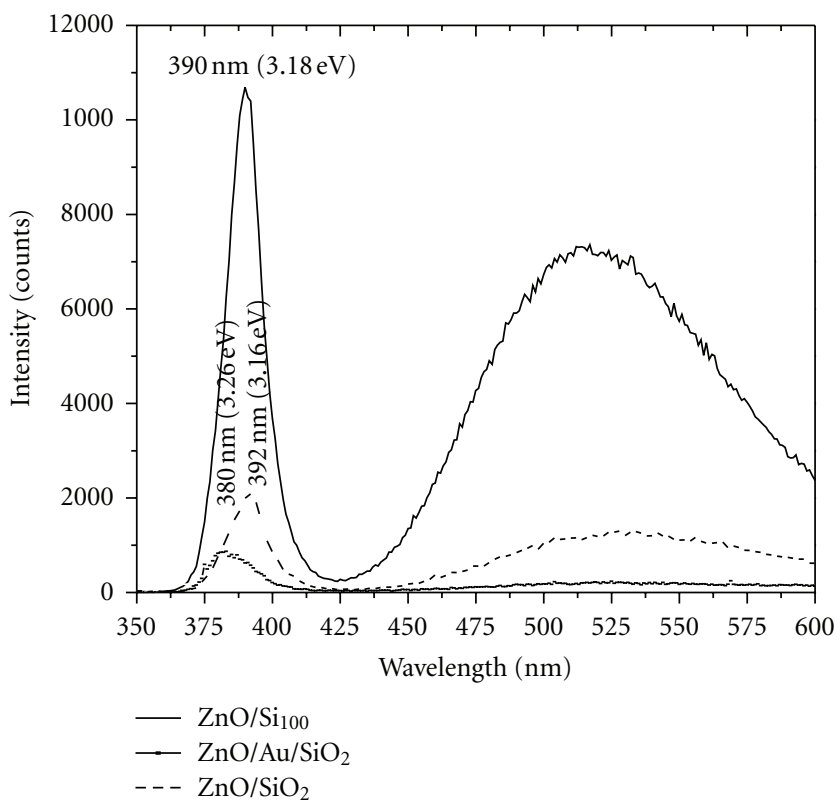

Figure 5: Room temperature CL spectra of $\mathrm{ZnO}$ samples grown on three different substrates by PVD.

improve our understanding of the optical properties of the $\mathrm{ZnO}$ structures. Figure 5 shows the room temperature 


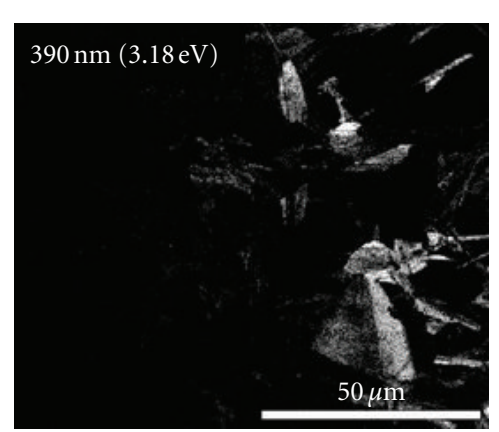

(a)

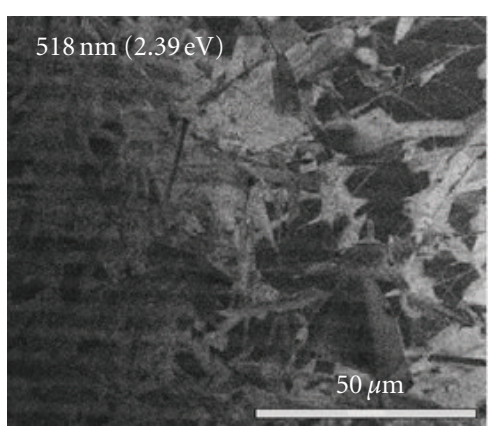

(b)

FIGURE 6: Monochromatic CL images of $\mathrm{ZnO}$ at the same region, (a) at wavelength of $390 \mathrm{~nm}$ mainly from flat surfaces (plaques) and (b) at $528 \mathrm{~nm}$, mostly from nanowires.

luminescence characteristic of $\mathrm{ZnO}$. The CL spectra of the three samples exhibit two broad peaks, one peak at around $390 \mathrm{~nm}(\sim 3.2 \mathrm{eV})$ near the band edge of the material and a broad peak centered at $525 \mathrm{~nm}(\sim 2.4 \mathrm{eV}$, the typical green emission). This green emission is the typical green emission for the undoped or unintentional doped $\mathrm{ZnO}$ which is attributed to oxygen vacancies $\left(\mathrm{V}^{+}\right)$[16-18]. Also, Janotti and Van de Walle [19] have presented a model for the formation energy of oxygen vacancies in $\mathrm{ZnO}$, which establishes a relationship between green emission and oxygen vacancies. Figure 6 shows monochromatic CL images of $\mathrm{ZnO}$ taken at the same location. In (a), it is possible to see that the $390 \mathrm{~nm}$ emission is from the flat surface, and in (b), we can see that the "green emission" is emitted principally from rods and wires. It gives the impression that the flat structures such as sheets and plaques have less oxygen vacancies $\left(\mathrm{V}^{+}\right)$than the cylindrical structures such as nanorods.

\section{Conclusions}

An improved PVD method to grow high-quality nanostructures of $\mathrm{ZnO}$ on different substrates had been investigated. This method is very straightforward; it can produce large quantities of $\mathrm{ZnO}$ in a short time without later treatments as thermal annealing and can produce less contaminated samples. X-ray diffraction confirms that the $\mathrm{ZnO}$ grown by this method presents a hexagonal wurtzite polycrystalline structure with a preferred growth direction (1011). These structures are attributed to the Au droplets which promote this orientation over the typical crystalline orientation (002) of $\mathrm{ZnO}$. These structures also show high-intensity luminescence in the UV $(390 \mathrm{~m}$,) and visible regions between 470 and $570 \mathrm{~nm}$. It was found that the $\mathrm{ZnO}$ flat structures such as sheets and plaques show higher intensity luminescence than those in $\mathrm{ZnO}$ rods and wires. Also, in this research was found that a selective growth can be achieved when the substrate presents well defined structures, such as the gold nanoislands to the precursors (zinc vapors and oxygen).

\section{Acknowledgments}

The authors gratefully acknowledge the use of facilities within the University of Sonora (UNISON), Arizona State
University (ASU), and Center of Nanoscience and Nanotechnology (CNyN-UNAM). This paper has been partially supported by CONACYT México, Project no. 102671.

\section{References}

[1] A. Osinsky, J. W. Dong, M. Z. Kauser et al., "MgZnO/AIGaN heterostructure light-emitting diodes," Applied Physics Letters, vol. 85, no. 19, pp. 4272-4274, 2004.

[2] M. Law, L. E. Greene, J. C. Johnson, R. Saykally, and P. Yang, "Nanowire dye-sensitized solar cells," Nature Materials, vol. 4, no. 6, pp. 455-459, 2005.

[3] W. I. Park, G. C. Yi, M. Kim, and S. J. Pennycook, "ZnO nanoneedles grown vertically on $\mathrm{Si}$ substrates by non-catalytic vapor-phase epitaxy," Advanced Materials, vol. 14, pp. 18411843, 2002.

[4] T. C. Lin, C. Y. Wang, L. H. Chan, D. Q. Hsiao, and H. C. Shin, "Growth and characterization of a high-purity $\mathrm{ZnO}$ nanoneedles film prepared by microwave plasma deposition," Journal of Vacuum Science \& Technology B, vol. 24, p. 1318, 2006.

[5] B. Liu and H. C. Zeng, "Hydrothermal synthesis of $\mathrm{ZnO}$ nanorods in the diameter regime of $50 \mathrm{~nm}$," Journal of the American Chemical Society, vol. 125, pp. 4430-4431, 2003.

[6] B. Cheng and E. T. Samulski, "Hydrothermal synthesis of onedimensional $\mathrm{ZnO}$ nanostructures with different aspect ratios," Chemical Communications, pp. 986-987, 2004.

[7] Z. Dong, B. Han, S. Qian, and D. Chen, "Fluorescent properties of $\mathrm{ZnO}$ nanostructures fabricated by hydrothermal method," Journal of Nanomaterials, vol. 2012, Article ID 251276, 5 pages, 2012.

[8] Y. Li, G. W. Meng, L. D. Zhang, and F. Phillipp, “Ordered semiconductor $\mathrm{ZnO}$ nanowire arrays and their photoluminescence properties," Applied Physics Letters, vol. 76, Article ID 2011, 2000.

[9] B. Cao, W. Cai, G. Duan, Y. Li, Q. Zhao, and D. Yu, "A template-free electrochemical deposition route to $\mathrm{ZnO}$ nanoneedle arrays and their optical and field emission properties," Nanotechnology, vol. 16, no. 11, pp. 2567-2574, 2005.

[10] B. Cao, X. Teng, S. H. Heo, Y. Li, S. O. Cho, and W. J. Cai, "Different $\mathrm{ZnO}$ nanostructures fabricated by a seed-layer assisted electrochemical route and their photoluminescence and field emission properties," Physical Chemistry C, vol. 111, p. 2470, 2007.

[11] L. F. Xu, Y. Guo, Q. Liao, J. P. Zhang, and D. S. Xu, "Morphological control of $\mathrm{ZnO}$ nanostructures by electrodeposition," 
The Journal of Physical Chemistry B, vol. 109, Article ID 13519, 2005.

[12] E. Gungor and T. Gungor, "Effect of the substrate movement on the optical properties of $\mathrm{ZnO}$ thin films deposited by ultrasonic spray pyrolysis," Advances in Materials Science and Engineering, Article ID 594971, 7 pages, 2012.

[13] M. H. Huang, S. Mao, H. Feick et al., "Room-temperature ultraviolet nanowire nanolasers," Science, vol. 292, no. 5523, pp. 1897-1899, 2001.

[14] Z. W. Pan, Z. R. Dai, and Z. L. Wang, "Nanobelts of semiconducting oxides," Science, vol. 291, no. 5510, pp. 1947-1949, 2001.

[15] H. T. Ng, J. Li, M. K. Smith et al., "Growth of epitaxial nanowires at the junctions of nanowalls," Science, vol. 300, no. 5623, p. $1249,2003$.

[16] M. S. Wang, K. E. Lee, and S. H. Hahn, "Optical and photoluminescent properties of sol-gel Al-doped $\mathrm{ZnO}$ thin films," Materials Letters, vol. 61, pp. 1118-1121, 2007.

[17] K. Vanheusden, W. L. Warren, C. H. Seager, D. R. Tallant, J. A. Voigt, and B. E. Gnade, "Mechanisms behind green photoluminescence in $\mathrm{ZnO}$ phosphor powders," Journal of Applied Physics, vol. 79, no. 10, pp. 7983-7990, 1996.

[18] X. L. Wu, G. G. Siu, C. L. Fu, and H. C. Ong, "Photoluminescence and cathodoluminescence studies of stoichiometric and oxygen-deficient ZnO films," Applied Physics Letters, vol. 78, Article ID 2285, 2001.

[19] A. Janotti and C. G. Van de Walle, "Oxygen vacancies in $\mathrm{ZnO}$," Applied Physics Letters, vol. 87, Article ID 122102, 2005. 

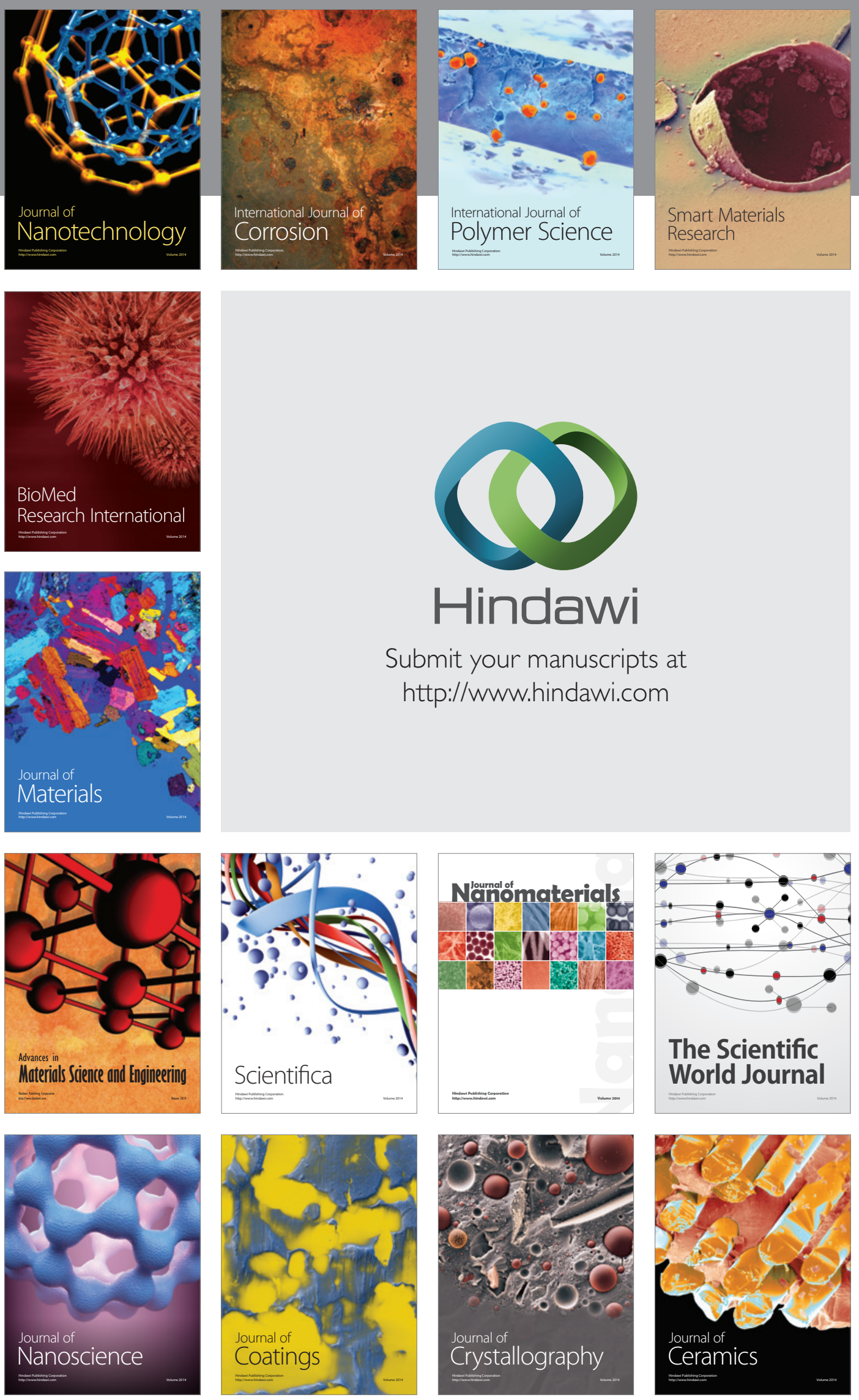

The Scientific World Journal

Submit your manuscripts at

http://www.hindawi.com

\section{World Journal}

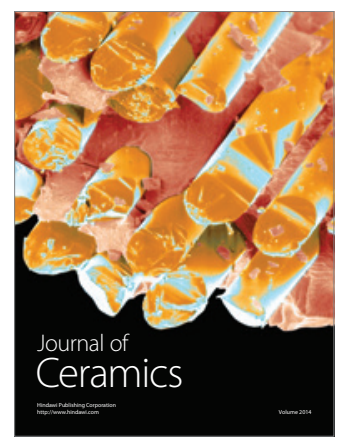

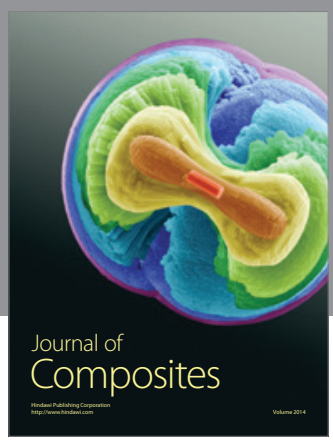
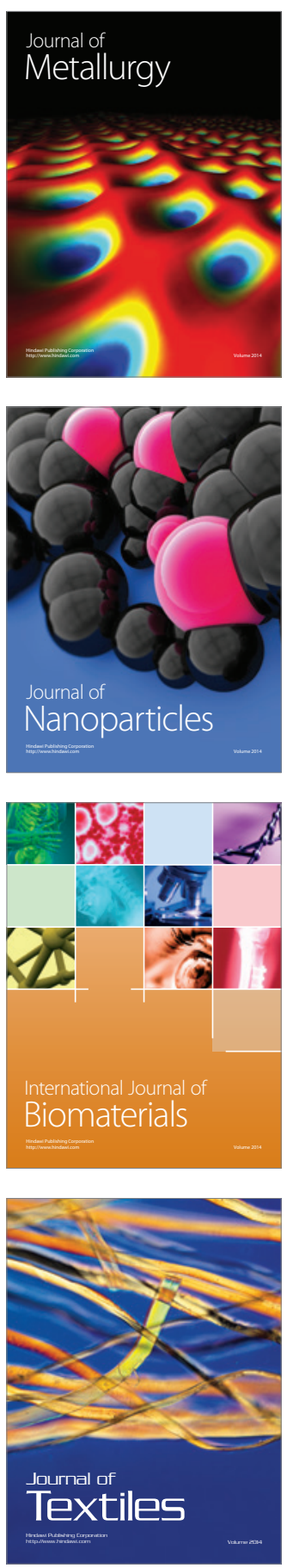